\title{
Adsorption of Atoms on Cubic $\beta$-MoC (001) Surface
}

\author{
José R. S. Politi \& Alanna P. C. Dantas
}

\section{Introdução}

$\mathrm{O}$ metano é um dos principais poluentes industriais e tem várias aplicações nas mais diversas áreas, sendo alvo de inúmeros estudos. Um dos processos mais utilizados para o uso racional desse gás é a reforma à vapor. Nesse processo o metano é convertido em uma mistura de hidrogênio e monóxido de carbono. Essa mistura é conhecida como gás de síntese e é muito utilizada como insumo em várias indústrias de transformação, como, por exemplo na produção de amônia e síntese de hidrocarbonetos via processos Fischer-Tropsch. Contudo, a reforma à vapor é um processo caro industrialmente principalmente pelo uso de metais nobres como catalisadores. Por isso há grande interesse no estudo de catalisadores mais baratos para essa reação.

A adsorção é uma das principais etapas na catálise heterogênea, pois é através da formação de novas estruturas, resultantes da adsorção das moléculas do meio sobre o catalisador, que ocorrem as modificações nos mecanismos que promovem o aumento da taxa de reação. a demanda por tecnologias mais econômicas e com menor impacto ambiental vem crescendo, e segundo Basta et al (1994), esse é um dos fatores que mais contribuem para o desenvolvimento da técnica de adsorção química ${ }^{1,2}$.

Os carbetos de metais de transição (TMC) têm se mostrado catalisadores promissores em diversas reações estudadas. Estudos publicados na literatura de nanopartículas de ouro suportadas em TiC se mostraram excelentes catalisadores para a dissociação de oxigênio ${ }^{3}$ e a dessulfuração do tiofeno. ${ }^{4}$

A extensão desse estudo para nanopartículas de prata e cobre mostrou que essas estruturas têm propriedades catalíticas ainda melhores para a dissociação de compostos contendo enxofre orgânico. ${ }^{5}$ A atividade catalítica de superfícies de nanopartículas metálicas é bem conhecida, mas a importância do suporte de carbeto no processo catalítico também foi recentemente provada, devido ao processo de polarização. ${ }^{6}$

Nesse contexto, define-se o objetivo desse trabalho que é estudar a adsorção dos átomos de níquel, rutênio, platina e paládio na superfície do $\delta$-MoC $(001)$.

\section{Metodologia}

Nesse estudo foi utilizado o método periódico para representar o sistema sólido e evitar o efeito de borda existente nos estudos de sólidos. Em particular, modelos periódicos de representação de sólidos associados a níveis sofisticados de aproximação são potencialmente úteis para descrever e interpretar aspectos dos fenômenos regidos pelas características eletrônicas, estruturais e de reatividade de sólidos. Os cálculos foram realizados com a teoria do funcional densidade (DFT), dentro da aproximação GGA. Foram utilizados os funcionais PBE e PW91, implementados no programa VASP. Nessa estratégia, a densidade dos elétrons de valência são expandidas em um conjunto de bases de ondas planas e o efeito provocado pelos elétrons internos é descrito pelo 
método PAW (projector augmented wave) de Blöch. O método DFT empregado nesse projeto tem se mostrado o método ab initio mais adequado para esse tipo de estudo, apresentando uma boa acurácia quando comparado a dados experimentais e teóricos.

\section{Resultados e Discussão}

Foram propostos diferentes sítios de adsorção, com o intuito de determinar em qual deles ocorre a interação mais favorável. A adsorção de um único átomo na estrutura cúbica do $\delta$-MoC foi provada nos sítios bridge, hollow, topC e topM, mostrados na figura a seguir.

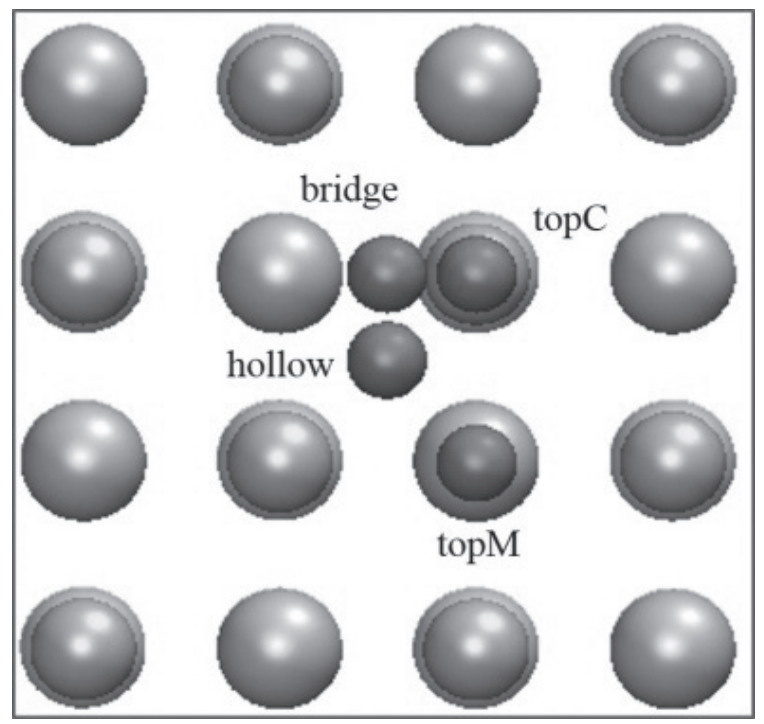

Figura 1. Sítios de adsorção na superfície $\delta$-MoC

O sítio hollow foi o que apresentou a menor energia de adsorção para os adátomos (ad) selecionados. Na tabela a seguir, são apresentadas essas energias de adsorção.

Energia de adsorção (ev) dos adátomos (ad) na posição hollow

\begin{tabular}{|c|c|c|c|c|}
\hline Ad & Ni & Pd & Pt & Ru \\
\hline Eads $(\mathrm{eV})$ & 4,9292 & 4,4067 & 4,9575 & 7,0247 \\
\hline
\end{tabular}

Ao serem adsorvidos, todos os átomos promoveram uma reconstrução da superfície (001) do $\delta$-MoC. Os átomos de carbono se deslocam na direção do metal adsorvido e os de molibdênio se afastam (figura 2).

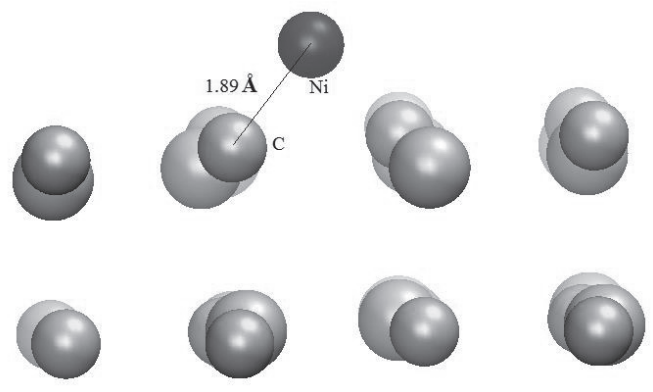

Figura 2. Átomo de Ni adsorvido na superfície 001 do $\delta$-MoC

A carga sobre o Ni varia em $+0,1$ na adsorção. Variação semelhante ocorre com os demais átomos.

\section{Conclusão}

Os átomos de níquel, paládio, platina e rutênio foram adsorvidos pela superfície. É possível observar a ocorrência de reconstrução na superfície com a adsorção desses átomos. $\mathrm{O}$ comprimento de ligação e as energias envolvidas indicam que essas adsorções são químicas. Há um leve aumento da carga dos átomos quando ocorre a adsorção, significando uma transferência de carga do adátomo para a superfície. Essa transferência torna a superfície ligeiramente mais oxidativa, o que sugere que esses adátomos favorecem a ação catalítica da superfície.

\section{Agradecimentos}

Os autores agradecem o suporte fornecido para a realização deste trabalho: UnB; CENAPAD SP; FAPDF; CNPq e CAPES.

\section{Referências}

1. J. A. Rodriguez, L. Feria, T. Jirsak, Y. Takahashi, K. Nakamura, and F. Illas, J. Am. Chem. Soc. 132 (9), 3177(2010).

2. J. A. Rodriguez, P. Liu, Y. Takahashi, K. Nakamura, F. Vines, and F. Illas, J. Am. Chem. Soc. 131 (24), 8595 (2009); Rodriguez, JA 
, Liu, P, Takahashi, Y., Vines, F., Feria, L., Florez, E., Nakamura, K. , Illas, F. , Catalysis Today 166 (1), 2 (2011)

3. Lee, J., S. Oyama, and M. Boudart, Molybdenum carbide catalysts: I. Synthesis of unsupported powders. Journal of Catalysis, 1987. 106(1): p. 125-133.

4. Leclercq, G., et al., Treatment of bulk group VI transition metal carbides with hydrogen and oxygen. Applied Catalysis A:

General, 1995. 121(2): p. 169-190.

\section{José R. S. Politi* \& Alanna de Pádua Carieli Dantas}

Universidade de Brasília, Instituto de Química, Campus Universitário Darcy Ribeiro, Brasília - BRAZIL

*E-mail: politi@unb.br 